\title{
AVALIAÇÃO INSTITUCIONAL DA QUALIDADE EM SERVIÇOS EDUCACIONAIS NA PERCEPÇÃO DE ALUNOS DE CURSOS TÉCNICOS Ả DISTÂNCIA
}

\author{
César Cândido de Brito \\ Instituto Federal de Educação, Ciência e Tecnologia Goiano \\ DOI: 10.15628/rbept.2018.6308
}

Artigo submetido em set/2017 e aceito em mar/2018

\begin{abstract}
RESUMO
Este estudo investiga os principais atributos para avaliar a qualidade institucional dos serviços educacionais oferecidos aos alunos dos cursos técnicos a distância realizado pelo Instituto Federal de Educação, Ciência e Tecnologia Goiano em parceira com a Rede e-Tec a luz dos modelos SERVQUAL desenvolvidos por Parasuraman, Zeithaml e Berry (1985, 1988); SERPERF desenvolvidos por Cronin e Taylor (1992) e HEdPERF desenvolvido por Firdaus $(2005,2006)$. Sob a forma de estudo de caso, os resultados obtidos através de entrevistas semiestruturadas, foram analisados por meio da análise de conteúdo de Bardin (1977), a partir de oito categorias a priori foram identificadas 18 subcategorias que emergiram do texto transcrito das narrativas dos entrevistados, especificando os atributos de satisfação e qualidade dos serviços na instituição pesquisada. Conclui-se que a junção dos modelos proposta permite verificar e avaliar as discrepâncias existentes na qualidade dos serviços oferecidos, identificar as prioridades para se alcançar a satisfação dos clientes, mostrando ser uma ferramenta útil para orientar os gestores na elaboração de estratégias competitivas e de melhoria contínua.
\end{abstract}

Palavras-chave: Atributos. Qualidade. Serviço. Instituições. Ensino.

\section{INSTITUTIONAL EVALUATION OF QUALITY IN EDUCATIONAL SERVICES IN THE PERCEPTION OF STUDENTS OF DISTANCE TECHNICAL COURSES}

\begin{abstract}
This study investigates the main attributes to evaluate the quality of the educational services offered to the students of the distance technical courses carried out by the Federal Institute of Education, Science and Technology Goiano in partnership with the e-Tec Network in light of the SERVQUAL models developed by Parasuraman, Zeithaml And Berry (1985, 1988); SERPERF developed by Cronin and Taylor (1992) and HEdPERF developed by Firdaus (2005, 2006). In the form of a case study, the results obtained through semi-structured interviews were analyzed through the content analysis of Bardin (1977), from eight a priori categories were identified 18 subcategories that emerged from the transcribed text of the interviewees narratives, Specifying the attributes of satisfaction and quality of services in the institution surveyed. It is concluded that the combination of the proposed models allows verifying and evaluating the existing discrepancies in the quality of services offered, identifying the priorities to achieve customer satisfaction, proving to be a useful tool to guide managers in the elaboration of competitive strategies and improvement to be continued.
\end{abstract}

Keywords: Attributes. Quality. Service. Institutions. Teaching. 


\section{INTRODUÇÃO}

Um novo cenário se mostra presente na sociedade do século $X X I$ altamente competitiva e globalizada. Nesse novo ambiente, prestar serviços de qualidade é a chave para o desenvolvimento e progresso de governos e empresas. Vários segmentos do mercado empresarial e do setor público implementam programas de qualidade, agregando valor e diferenciação aos produtos e serviços, com a intenção de reter e satisfazer às necessidades do público alvo. Na Gestão Pública as reformas administrativas ocorridas no Brasil a partir da última década do século passado, vêm ao encontro desse objetivo, tendo como principais metas a melhoria da qualidade dos serviços na administração pública e atender às demandas do cidadão (DI GIACOMO, 2005).

Essa preocupação por parte do governo em relação a qualidade está presente também na educação por meio do Plano Nacional de Educação 2014/2024 - PNE, que determina diretrizes, metas e estratégias para a política educacional dos próximos dez anos. A lei 13.005, de 25 de junho de 2014 que aprovou o PNE e dá outras providências destaca no Art. 2ำ que entre suas diretrizes está a melhoria na qualidade da educação (BRASIL, 2014).

No tocante a educação técnica, o PNE tem como meta triplicar as matrículas da educação profissional técnica de nível médio, assegurando a qualidade da oferta e pelo menos cinquenta por cento da expansão no segmento público. Entre as estratégias desenvolvidas para alcançar este objetivo, encontra-se a Escola Técnica Aberta do Brasil (Rede e-Tec), uma das ações que integram o Programa Nacional de Acesso ao Ensino Técnico e Emprego (PRONATEC), e que visa à oferta de educação profissional e tecnológica a distância e tem o propósito de ampliar e democratizar o acesso a cursos técnicos de nível médio, públicos e gratuitos, em regime de colaboração entre União, estados, Distrito Federal e municípios.

Procurando contribuir com os estudos sobre qualidade na educação a distância, este estudo se propõe a pesquisar e apontar o nível de satisfação dos alunos quanto ao padrão de qualidade institucional dos cursos técnicos 
na modalidade a distância, realizados pelo IF Goiano em parceria com a Rede e-Tec Brasil.

Segundo Walter, Tontini e Domingues (2005, p. 1), "o mercado educacional aproxima-se cada vez mais de um mercado onde a qualidade dos serviços e a satisfação dos clientes são fundamentais para a sobrevivência das IES”. Diante da sua importância, mensurar a percepção da qualidade em serviços possibilita aos gestores dimensionar o grau de qualidade, tomar decisões de planejamento visando planos de ações para alcançar os objetivos organizacionais (KOTLER, 2000). No setor público que vive um constante ambiente de crise financeira, uma gestão eficaz requer a tomada de decisão apropriada, como afirmam Dinsdale et al, (2000, p. 92), "em um contexto de restrições fiscais, as organizações de serviços públicos dependem do feedback de seus públicos alvos, para tornar as decisões efetivas a respeito dos serviços prestados".

Contudo, a literatura educacional brasileira que discute a questão da qualidade no ensino ressalta a complexidade, o caráter polêmico, a natureza histórica e o caráter de classe (BEISIEGEL, 2005; OLIVEIRA E ARAÚJO, 2005; DOURADO E OLIVEIRA, 2009; FERREIRA E TENÓRIO, 2010; OLIVEIRA, 2009). Segundo Klauck (2012), há falta de clareza, de consenso e as disputas em torno da questão não são de ordem meramente conceitual, mas de projetos políticos para o País, o que torna a qualidade em educação um tema atual e de interesse de todas as classes sociais, além de uma abordagem continuamente aberta à pesquisa. Destaque-se ainda que o processo de avaliação sempre foi um tema polêmico, pois permite a emissão de um juízo de valor sobre a qualidade das atividades, produtos, serviços e profissionais que atuem na Instituição.

No entanto, é necessário que as organizações sejam avaliadas para a garantia da qualidade, objetivando colocar no mercado de trabalho profissionais dotados de competências cada vez mais abrangentes, sofisticadas e inovadoras, apto para se estabelecer no mercado profissional altamente competitivo. Dessa forma, identificar os atributos e dimensões da qualidade dos serviços educacionais torna-se relevante para se atender as expectativas dos futuros profissionais. 
Com foco no cliente, esta pesquisa busca responder a seguinte questão: quais os principais atributos para avaliar a qualidade institucional dos cursos técnicos a distância na perspectiva dos alunos? Para responder a esta questão o estudo utiliza os atributos de qualidade apresentados pelas metodologias SERVQUAL desenvolvidos por Parasuraman, Zeithaml e Berry (1985, 1988); SERPERF por Cronin e Taylor (1992) e HEdPERF por Firdaus (2005, 2006) que são ferramentas mundialmente utilizadas pelos pesquisadores para mensurar a qualidade em serviços.

\section{QUALIDADE EM SERVIÇO}

A concepção de serviço e o construto da qualidade são conceitos importantes a serem definidos neste trabalho. Autores como Oliver (1980), Parasuraman, Zeithaml e Berry (1985, 1988), Zeithaml e Bitner (2003), Grönroos (2003), Zeithaml, Bitner e Gremler (2011), Hoffman e Bateson (2003), Lovelock e Wirtz (2006), Kotler e Keller (2006), Fitzsimmons e Fitzsimmons (2010) em muito contribuíram em seus estudos e pesquisas sobre qualidade em serviços, ocasionado pelo crescimento do mercado de serviços, que passou a influenciar a economia em vários países do mundo, com participação significativa no Produto Interno Bruto - PIB.

No referencial teórico desta pesquisa discorre-se sobre serviços e suas características e também sobre o conceito de qualidade com foco em serviços educacionais. Em seguida, apresentam-se os instrumentos de mensuração da qualidade em serviços: SERVQUAL, SERVPERF e o modelo HEdPERF, este último específico de avaliação da qualidade em serviços educacionais.

\subsection{Serviços}

O setor de serviços vem ganhando destaque na economia mundial, afinal a sociedade atual busca cada vez mais consumir não somente de produtos, mas também de experiências que possam proporcionar prazer e bem-estar. Segundo Fitzsimmons e Fitzsimmons (2010), a humanidade está presenciando a maior migração de mão de obra desde a revolução industrial. A migração da agricultura e da manufatura para os serviços impulsionada 
sobretudo pelas comunicações globais, pelo crescimento dos negócios e da tecnologia, pela urbanização e pelo baixo custo da mão de obra. Ainda segundo Fitzsimmons e Fitzsimmons (2010) os setores de serviços são líderes em todas as nações industrializadas, criam novos empregos que dominam as economias nacionais e tem o potencial de melhorar a qualidade de vida de todos.

$\mathrm{Na}$ literatura são muitas as definições de serviços, mas todas têm em comum as características da intangibilidade, inseparabilidade, variabilidade e perecibilidade. Entende-se por serviço, uma atividade intangível, intransferível, não transportável, que supre determinadas necessidades e que criam valor e fornecem benefícios para a outra parte (KOTLER, KELLER, 2006; ZEITHAML, BITNER, 2003; LOVELOCK, WRIGHT, 2002). Na visão de Grönroos (2003, p. 65):

Um serviço é um processo, consistindo em uma série de atividades mais ou menos intangíveis que, normalmente, mas não necessariamente sempre, ocorrem nas interações entre cliente e os funcionários de serviço e/ou recursos ou bens físicos e/ou sistemas do fornecedor de serviços e que são fornecidos como soluções para problemas do cliente.

Contudo, Grönroos (2003) defende como sendo mais proveitoso observar e discutir as características que parecem ser comuns a maioria dos serviços, do que persistir em um debate estéril sobre seu conceito e definição, apesar das inúmeras contribuições de diversos autores e estudiosos sobre o tema. Neste sentido, Grönroos (2003) destaca as várias características específicas relacionadas aos serviços, as quais se diferenciam dos bens. Sinteticamente, podem ser distinguidos dos bens físicos conforme Quadro 1.

Quadro 1 - Diferença entre Serviços e Bens

\begin{tabular}{|c|c|}
\hline SERVIÇOS & BENS FíSICOS \\
\hline Intangível & Tangível \\
\hline Heterogêneo & Homogêneo \\
\hline Uma atividade ou processo & Uma coisa \\
\hline $\begin{array}{c}\text { Produção, distribuição e consumo são processo } \\
\text { simultâneos }\end{array}$ & $\begin{array}{c}\text { Produção e distribuição separadas do } \\
\text { consumo }\end{array}$ \\
\hline $\begin{array}{c}\text { Valor principal produzido nas interações entre } \\
\text { comprador e vendedor }\end{array}$ & $\begin{array}{c}\text { Valor principal produzido em fábrica } \\
\text { Clientes participam da produção }\end{array}$ \\
\hline $\begin{array}{c}\text { Clientes normalmente não participam do } \\
\text { processo de produção }\end{array}$ \\
\hline
\end{tabular}


\begin{tabular}{|c|c|}
\hline Não pode ser mantido em estoque & Pode ser mantido em estoque \\
\hline A propriedade não pode ser transferida & A propriedade pode ser transferida \\
\hline
\end{tabular}

Fonte: Grönroos (2003).

As características gerais dos serviços são quase universalmente aceitas (COELHO, 2004), não importando a natureza ou o tipo de serviço analisado. Contudo, dependendo do grau de interação com o cliente e da natureza do serviço, variam a importância de cada característica, do tipo de recurso a ser utilizado e de como os processos de prestação de serviços são gerenciados. Um dos tipos de prestação de serviço que condizem com esta realidade é o setor de educação. Neste sentido, Carvalho (2009, p. 13) destaca que:

\footnotetext{
Este setor possui grande participação do cliente ao longo do processo, pois representa uma atividade que processa informações e conhecimento possuindo componentes intangíveis mais relevantes que os tangíveis (embora estes sejam essenciais para a sua prestação.
}

Destaque-se ainda que o comportamento de escolha do consumidor é influenciado pela qualidade percebida do serviço, podendo determinar comportamentos tais como a sua continuidade e o grau de intensidade com o qual este cliente vai se relacionar com a organização (HENNIG-THURAU; LANGER; HANSEN, 2001).

Neste sentido, torna-se relevante pesquisar os atributos $\mathrm{e}$ as dimensões que compõe a qualidade percebida dos serviços educacionais e que influenciam a escolha do consumidor.

\subsection{Qualidade}

Estudos acerca de qualidade vem evoluindo desde a revolução industrial e, ao longo do século XX. A busca de padrões de qualidade em suas diferentes acepções se incorporou definitivamente às teorias e às práticas empresariais.

Para Andretti (2006), tem-se que qualidade possui diversos significados, como um conceito subjetivo que está diretamente relacionado às percepções de cada pessoa. Embora a concepção de qualidade exista a 
muito tempo, o termo tem diversas utilizações, o seu significado nem sempre é compreensível. Contudo, independente do conceito utilizado, são essenciais a clareza e a objetividade do seu significado e que esteja perfeitamente entendido e em uma linguagem acessível para todos os membros de uma organização.

Conforme Quadro 2 organizado por Poffo e Marinho (2013), na literatura pode-se elencar nove conceitos para caracterização da qualidade. Cada autor apresenta sua visão e características diferentes para o conceito de qualidade.

Quadro 2 - Significados da Palavra Qualidade

\begin{tabular}{|c|c|l|}
\hline ANO & AUTOR & \multicolumn{1}{|c|}{ SIGNIFICADO DA PALAVRA QUALIDADE } \\
\hline 1974 & J. M. Juran & $\begin{array}{l}\text { O nível de satisfação alcançado por um determinado produto no } \\
\text { atendimento aos objetivos do usuário, durante o seu uso, é chamado de } \\
\text { adequação ao uso. Este conceito de adequação ao uso, popularmente } \\
\text { conhecido por alguns nomes, tal com qualidade, é um conceito } \\
\text { universal aplicável a qualquer tipo de bem ou serviço. }\end{array}$ \\
\hline 1979 & Philip Crosby & $\begin{array}{l}\text { Qualidade quer dizer conformidade com os requisitos. Qualidade é o } \\
\text { atendimento às especificações definidas para satisfazerem os usuários. }\end{array}$ \\
\hline 1986 & $\begin{array}{c}\text { Kaoru } \\
\text { Ishikawa }\end{array}$ & $\begin{array}{l}\text { Qualidade é o desenvolvimento, projeto, produção e assistência de um } \\
\text { produto ou serviço que seja o mais econômico possível e o mais útil } \\
\text { possível, proporcionando satisfação ao usuário. }\end{array}$ \\
\hline 1990 & $\begin{array}{c}\text { Wiliam E. } \\
\text { Deming }\end{array}$ & $\begin{array}{l}\text { Qualidade consiste na capacidade de satisfazer desejos do cliente e } \\
\text { melhoria contínua. }\end{array}$ \\
\hline 1991 & $\begin{array}{l}\text { Armand } \\
\text { Feigenbaun } \\
\text { são: o verdadeiro uso e o preço de venda do produto. Qualidade e a } \\
\text { composição total das características de marketing, engenharia, } \\
\text { fabricação e manutenção de um produto ou serviço, através das quais o } \\
\text { mesmo produto ou serviço, em uso, atenderá as expectativas do } \\
\text { cliente. }\end{array}$ \\
\hline 1994 & Paladini & $\begin{array}{l}\text { Qualidade corretamente definida é aquela que prioriza o consumidor. } \\
\text { Isto mostra que a qualidade é mais do que simples estratégias ou } \\
\text { técnicas é, antes, uma questão de decisão que reflete em políticas de } \\
\text { funcionamento da organização. }\end{array}$ \\
\hline
\end{tabular}

Fonte: Poffo e Marinho (2013).

Analisando a qualidade segundo os enfoques apresentados, percebese que todos os conceitos são coerentes e um reforça o outro, pois enfatizam aspectos fundamentais para o desenvolvimento da qualidade, sendo que, em todas as abordagens, o foco principal é o cliente. Nesse sentido, faz-se necessário o entendimento do processo de avaliação da qualidade percebida em serviço, pois permite compreender a forma de sua atuação, prevenindo e solucionando as lacunas de qualidade, aumentando a produtividade e 
agregando valor aos serviços, consequentemente elevando a satisfação dos clientes.

\subsection{Avaliação da Qualidade Percebida em Serviço}

No início da década de 1980, começou-se a discutir a qualidade para o setor de serviços no Brasil, tanto no meio acadêmico quanto empresarial, buscando-se uma definição que abrangesse as expectativas, as percepções e as estratégias organizacionais (GUMMESSON, 1994). Souza, Silva e Rodrigues (2004) destacam que dois modelos teóricos dominam os estudos sobre a percepção da qualidade dos serviços: paradigma da desconfirmação e teoria da performance.

O paradigma da desconfirmação relatado por Oliver (1980) parte de um processo de comparação do serviço percebido com o serviço desejado, sendo que a desconfirmação positiva gera a satisfação e a desconfirmação negativa gera a insatisfação.

Essa linha de raciocínio também é compartilhada por Parasuraman, Zeithaml e Berry (1985) e Grönroos (2003) que analisam a qualidade percebida em serviços como a diferença entre as percepções e as expectativas. Segundo os autores, a percepção do consumidor em relação a qualidade do serviço depende da diferença entre a expectativa e o desempenho do serviço prestado

Baseados no paradigma da desconfirmação de Oliver (1980), Parasuraman, Zeithaml e Berry $(1985,1988)$ defendem um modelo de lacunas da qualidade de serviços para explicar as principais causas de insatisfação em relação aos serviços. A diferença entre serviço percebido e serviço esperado foi denominado lacuna (gap). Esses gaps podem ser o principal obstáculo para que os usuários percebam a prestação desses serviços como sendo de alta qualidade.

Dando continuidade ao modelo dos gaps, Parasuraman, Zeithaml e Berry $(1985,1988)$ no intuito de entender como os usuários percebiam e avaliavam a qualidade dos serviços, desenvolveram um instrumento de mensuração da qualidade percebida em serviços denominada de Service Quality - SERVQUAL. 
Originalmente o modelo desenvolvido por Parasuraman, Berry e Zeithaml $(1985,1988)$ compreendia dez atributos e dimensões de qualidade que posteriormente foram reduzidos a cinco, por meio da redefinição de alguns pontos e da substituição de outros. Os atributos resultantes foram: tangibilidade, confiabilidade, responsividade/presteza, garantia/segurança e empatia, como demonstrado no Quadro 3.

Quadro 3 - Os Atributos e Dimensões de Qualidade de Parasuraman, Berry e Zeithaml

\begin{tabular}{|c|c|c|}
\hline $\begin{array}{l}\text { MODELO } \\
\text { ORIGINAL }\end{array}$ & $\begin{array}{c}\text { MODELO } \\
\text { ESTRUTURADO }\end{array}$ & DESCIRÇÃO/ATRIBUTOS \\
\hline Tangibilidade & Tangibilidade & $\begin{array}{c}\text { Corresponde a aparência das instalações } \\
\text { físicas, equipamentos, pessoal e materiais } \\
\text { para comunicação. }\end{array}$ \\
\hline Confiabilidade & Confiabilidade & $\begin{array}{c}\text { É a habilidade de prestar um serviço } \\
\text { conforme o prometido com confiança e de } \\
\text { forma correta. }\end{array}$ \\
\hline $\begin{array}{l}\text { Responsividade/ } \\
\text { Presteza }\end{array}$ & Responsividade/Presteza & $\begin{array}{l}\text { É a disposição em ajudar os clientes, } \\
\text { fornecendo prontamente os serviços. }\end{array}$ \\
\hline Competência & \multirow{4}{*}{ Garantia/segurança } & \multirow{4}{*}{$\begin{array}{c}\text { É o conhecimento e a cortesia dos } \\
\text { funcionários, transmitindo confiança; } \\
\text { incluindo características como: competência } \\
\text { para realizar o serviço, cortesia e respeito ao } \\
\text { cliente; }\end{array}$} \\
\hline Cortesia & & \\
\hline Credibilidade & & \\
\hline Segurança & & \\
\hline Acesso & \multirow{3}{*}{ Empatia } & \multirow{3}{*}{$\begin{array}{l}\text { É demonstrar interesse e atenção } \\
\text { individualizada aos clientes; }\end{array}$} \\
\hline Comunicação & & \\
\hline $\begin{array}{l}\text { Compreendendo } \\
\text { o Usuário }\end{array}$ & & \\
\hline
\end{tabular}

Fonte: Adaptado de Parasuraman, Zeithaml e Berry $(1985,1988)$.

A escala SERVQUAL possui duas seções: uma destinada ao mapeamento das expectativas do cliente em relação a um determinado segmento de serviço e outra destinada ao mapeamento da percepção dos serviços oferecidos por determinada empresa (FITZSIMMONS e FITZSIMMONS, 2010). Cada seção em sua forma original possui 22 questões para mensurar os cinco atributos de qualidade de serviços. Estas questões devem ser avaliadas em uma escala Likert de 1 a 7 , onde os extremos são marcados como concordo totalmente (excelente) e discordo totalmente (medíocre).

Os resultados das duas seções (percepção e expectativas) são comparados para se chegar a um parâmetro para cada uma das questões, ou 
seja, a pontuação final é gerada pela diferença entre elas, logo: qualidade = percepção - expectativa.

De acordo com o paradigma da desconformidade a qualidade percebida é considerada uma das variáveis formadoras da satisfação. Segundo Anderson et al. (1994) e Oliver (1993), a qualidade percebida é um construto distinto da satisfação. A primeira não precisa ser experimentada para ser percebida, enquanto, somente com a experiência do produto, é que o consumidor determina sua satisfação

Nesta perspectiva, em que satisfação do consumidor é uma consequência da qualidade percebida em serviços, e que a qualidade percebida em serviços é o resultado da comparação que os usuários fazem entre as suas expectativas sobre um serviço e a sua percepção do modo como o serviço foi executado, torna-se relevante identificar os atributos e dimensões considerados de qualidade pelo cliente, objetivando satisfazer o consumidor, haja vista, a qualidade percebida se compõe de atributos, os quais o consumidor confere uma importância relativa e que satisfaz suas necessidades ou expectativas (RAZAVI et al., 2012).

Diferente do que propõe o modelo do paradigma da desconfirmação onde o cliente compara a percepção que teve do serviço com a expectativa crida sobre o mesmo, Cronin Jr. e Taylor (1992) desenvolveram a teoria da performance defendendo que apenas o serviço percebido é fator de impacto na satisfação do cliente.

Seguindo essa linha de raciocínio, autores como Carman (1990), Babakus e Boller (1992), Cronin e Taylor (1992), Teas (1993) e Finn e Lamb (1991) fizeram várias críticas a escala SERVQUAL. Carman (1990) criticou o fato de que não era prático esperar que os usuários de um serviço completassem um inventário de expectativas antes da sua realização, e um inventário de percepções imediatamente após utilizá-lo. Babakus e Boller (1992) e Carman (1990) argumentam ainda que o uso da diferença entre percepções e expectativas não traz informações adicionais sobre a qualidade do serviço, uma vez que somente a aferição da performance se destaca na mensuração da qualidade percebida. 
Indo de encontro as críticas ao instrumento SERVQUAL, Joseph e Joseph (1997, p. 16) apontam algumas limitações ao emprego da SERVQUAL em educação:

1. É questionável a aplicabilidade das cinco dimensões identificadas como sendo os determinantes da qualidade de serviços. Até Parasuraman et al. (1988) declararam que a SERVQUAL deve ser customizada para cada setor, Cronin e Taylor (1992) e Carman (1990) afirmaram que o grau de customização necessário é mais alto do que Parasuraman et al. (1988) acreditam que é. Carman (1990) testou o SERVQUAL empiricamente em quatro diferentes setores e concluiu que tais dimensões não eram suficientemente genéricas para atender às necessidades de todos os setores.

2. Para que a mensuração baseada em desconfirmação funcione corretamente, as expectativas devem se manter constantes. A educação é um serviço de longo prazo e Carman (1990) sustenta que as expectativas mudam com a familiaridade que se tem com o serviço.

3. As expectativas são padrões contra as quais o desempenho pode ser mensurado. Esses padrões são formados nas bases do conhecimento e da experiência com o serviço. No caso da educação, os estudantes potenciais têm pouco ou nenhum conhecimento prévio e experiência com a educação de terceiro grau.

Parasuraman, Zeithaml e Berry (1994) responderam as críticas argumentando que a suposta superioridade de escalas não-diferenciais em relação à SERVQUAL é aparente, pois as escalas alternativas são praticamente equivalentes a esse modelo, tanto em validade quanto em confiabilidade, ademais, uma escala baseada apenas em percepções é mais econômica, porém mais ambígua, pois não inclui informações precisas sobre as causas de eventuais mudanças na noção de qualidade pelo consumidor.

Apesar das críticas a escala SERVQUAL tem sido utilizada para avaliar os mais diversos tipos de serviços, como hotelaria, educação e bancário, etc., os seus resultados têm colaborado para um melhor entendimento das questões relacionadas à qualidade nos serviços.

Discordando da ideia proposta na escala SERVQUAL, segundo as quais está teria sido suportada por fraca evidência teórica e empírica, Croning Jr. e Taylor (1992) sugerem um modelo que evidencie apenas na percepção dos usuários em relação a qualidade, denominado Service Performance SERVPERF. Croning Jr e Taylor (1992) entendem que apenas o serviço 
percebido é fator de impacto na satisfação do cliente. As características do SERVPERF são: 1. Derivada da SERVQUAL; 2. Componente "expectativa" da SERVQUAL foi eliminada, mantendo os 22 itens para a percepção; 3. Escala Likert de 7 pontos; 4. Não usa os gaps da SERVQUAL; 5. Redução de $50 \%$ no número de itens em relação à SERVQUAL.

Entre as conclusões das pesquisas de Cronin Jr e Taylor (1992), apontam a não confirmação dos cinco atributos SERVQUAL, propondo a operacionalização unidimensional das dimensões componentes da escala. A análise concluiu ainda que: 1. Uma medida da qualidade de serviço baseada na performance (SERVPERF) pode ser a melhor para se medir a qualidade de serviço; 2. A qualidade do serviço antecede a satisfação de um consumidor, por esta razão a qualidade será requisito para satisfação dos usuários; 3. A satisfação do consumidor tem um efeito significativo nas intenções de compra; 4. A qualidade do serviço tem menor efeito que a satisfação do consumidor nas intenções de compra.

Para Cronin Jr. e Taylor (1992), a qualidade de serviço deve ser medida numa escala atitudinal, baseada apenas na medida da performance, com a vantagem adicional de reduzir o tamanho do instrumento de pesquisa, facilitando sua operacionalização e melhor os índices de confiabilidade em comparação com a SERVQUAL.

Contudo, Parasuraman et al. (1994) criticou a escala SERVPERF ao afirmarem que em sua concepção o instrumento apresenta um menor grau de compreensão do consumidor, por não abordar seus desejos e expectativas. Entretanto, é comum encontrar na literatura pesquisadores que utilizaram em seus estudos uma abordagem híbrida, considerando a multidimensionalidade da escala SERVQUAL, porém focalizando apenas a qualidade percebida e não as expectativas em relação ao serviço.

\subsection{O modelo HEdPERF de Avaliação de Qualidade em Ensino Superior}

Após os estudos de Parasuraman, Zeithaml e Berry $(1985,1988)$ e Cronin Jr. e Taylor (1992), por meio das escalas SERVQUAL e SERVPERF, modelos que segundo seus idealizadores podem ser aplicados em qualquer segmento de mercado, Firdaus $(2005,2006)$ propõe um novo método que 
busca avaliar a qualidade dos serviços educacionais, denominado Higher Education Performance - HEdPERF.

O estudo de Firdaus (2006) objetivou o desenvolvimento e a validação do HEdPERF como uma nova escala de mensuração da qualidade de serviço, especificamente estruturado para o setor do ensino superior, usando técnicas quantitativas e qualitativas de medição, sendo o primeiro modelo com este enfoque.

Foram pesquisados 45 itens direcionados para avaliar os diferentes aspectos relativos aos serviços oferecidos pelas instituições de ensino. Firdaus (2006) afirma que a escala HEdPERF é válida e confiável. Após várias etapas da pesquisa, seis atributos (fatores) foram identificados, conforme Quadro 4.

Quadro 4 - Fatores de Avaliação da Qualidade em Serviços Educacionais.

\begin{tabular}{|c|c|c|}
\hline \multicolumn{2}{|c|}{ ATRIBUTO } & CONCEITO \\
\hline $\begin{array}{c}\text { Fator } \\
1\end{array}$ & $\begin{array}{c}\text { Aspectos não } \\
\text { acadêmicos }\end{array}$ & $\begin{array}{c}\text { Este fator contém variáveis que são essenciais para permitir aos } \\
\text { estudantes cumprir as obrigações de estudo. }\end{array}$ \\
\hline $\begin{array}{c}\text { Fator } \\
2\end{array}$ & $\begin{array}{c}\text { Aspectos } \\
\text { acadêmicos }\end{array}$ & $\begin{array}{c}\text { Este fator representa as responsabilidades de comunicação, } \\
\text { possibilitando discussões suficientes e estando apto a fornecer } \\
\text { uma avaliação regular. }\end{array}$ \\
\hline $\begin{array}{c}\text { Fator } \\
3\end{array}$ & Reputação & $\begin{array}{c}\text { Este fator é obtido com itens que sugerem a importância das } \\
\text { IES em projetar uma imagem profissional. }\end{array}$ \\
\hline $\begin{array}{c}\text { Fator } \\
4\end{array}$ & Acesso & $\begin{array}{c}\text { Este fator consiste de itens que relacionam questões como } \\
\text { proximidade, facilidade de contato, viabilidade e conveniência; }\end{array}$ \\
\hline $\begin{array}{c}\text { Fator } \\
5\end{array}$ & $\begin{array}{c}\text { Temas ou questões } \\
\text { dos programas }\end{array}$ & $\begin{array}{c}\text { Este fator enfatiza a importância de oferecer uma gama } \\
\text { extensiva e respeitável de programas/especializações } \\
\text { acadêmicas com estrutura e conteúdo flexíveis; }\end{array}$ \\
\hline $\begin{array}{c}\text { Fator } \\
6\end{array}$ & Compreensão & $\begin{array}{c}\text { Envolve itens relacionados com a compreensão das } \\
\text { necessidades específicas dos estudantes em termos de } \\
\text { aconselhamentos e a sua formação. }\end{array}$ \\
\hline
\end{tabular}

Fonte: Firdaus, 2005.

Segundo Firdaus (2006) todos os determinantes da qualidade do serviço, definidos pela pesquisa como sendo importante para a avaliação das IES, encontram-se descritos na literatura e são tidos como relevantes para vários autores. Contudo, vale ressaltar que os seis fatores determinantes da qualidade definidos pela pesquisa de Firdaus (2006) não corroboram com os cinco determinantes da qualidade da escala SERVQUAL de Parasuraman, Zeithaml e Berry (1988).

Posteriormente Firdaus (2006) refinou o modelo HEdPERF, reduzindo de seis para cinco atributos de avaliação da qualidade: aspectos não 
acadêmicos, aspectos acadêmicos, reputação, acessibilidade e conteúdo do programa. Conclui que embora a escala SERVPERF seja amplamente aceita como uma escala genérica, essa não previa perspectivas específicos para o ensino e que a HEdPERF com seus atributos engloba os 41 itens (direcionados para avaliar os diferentes aspectos relativos aos serviços oferecidos) pode ser o instrumento de medição mais adequado para a avaliação de instituições de ensino superior. Destaque-se ainda que o modelo HEdPERF visa determinar os fatores críticos da qualidade do serviço na visão dos alunos. No Quadro 8 apresenta um resumo dos modelos abordados nesta pesquisa.

Quadro 5 - Resumo dos Modelos SERQUAL, SERVPERF e HEdPERF.

\begin{tabular}{|c|c|c|c|}
\hline Autor & Modelo & Atributos da Qualidade & Aplicação \\
\hline $\begin{array}{c}\text { Parasuraman, et } \\
\text { al. (1985, 1988). }\end{array}$ & $\begin{array}{c}\text { SERVQUAL (44 Itens - } \\
\text { 22 avaliam a expectativa } \\
\text { e 22 avaliam o } \\
\text { desempenho) }\end{array}$ & $\begin{array}{c}\text { Aspectos tangíveis, } \\
\text { confiabilidade, presteza, } \\
\text { segurança e empatia }\end{array}$ & $\begin{array}{c}\text { Genérico: } \\
\text { aplicável a todo } \\
\text { os tipos de } \\
\text { serviços }\end{array}$ \\
\hline Cronin Jr., & $\begin{array}{c}\text { SERVPERF (22 Itens } \\
\text { que avaliam a } \\
\text { performance). }\end{array}$ & $\begin{array}{c}\text { Aspectos tangíveis, } \\
\text { confiabilidade, presteza, } \\
\text { segurança e empatia }\end{array}$ & $\begin{array}{c}\text { Genérico: } \\
\text { aplicável a todo } \\
\text { os tipos de } \\
\text { serviços }\end{array}$ \\
\hline Firdaus (2006) & HEdPERF (41 itens). & $\begin{array}{c}\text { Aspectos não acadêmicos, } \\
\text { aspectos acadêmicos, } \\
\text { reputação, acessibilidade e } \\
\text { conteúdo do programa. }\end{array}$ & Aplicável a IES \\
\hline
\end{tabular}

Fonte: Elaborado pelo autor (2016).

Diante dos diversos modelos de avaliação de qualidade existentes (SERVQUAL, SERVPERF, HEdPERF, etc.), Miguel e Salomi (2004), destacam que embora os trabalhos apresentados demonstrem que cada um dos modelos é teoricamente bem embasado e adequado para as aplicações propostas, pode-se afirmar que não existe ainda um consenso na literatura sobre qual modelo é mais apropriado.

A esse respeito Chagas (2010), conclui que devido à falta de consenso em relação ao modelo a ser usado para a avaliação da qualidade no setor de serviço, esta escolha fica a cargo do gestor que poderá optar por um dos modelos existentes fazendo as adaptações necessárias. 


\section{METODOLOGIA}

Os procedimentos metodológicos adotados neste estudo são de natureza exploratória com uma abordagem qualitativa, através de um estudo de caso, com aplicação de entrevistas semiestruturadas e utilização da técnica de Análise de Conteúdo.

Na medida em que há pouco conhecimento acumulado e sistematizado sobre a qualidade na prestação dos serviços prestados nos cursos técnicos a distância do IF Goiano, pode-se caracterizar este trabalho como exploratório, que segundo Gil (2008, p. 27) "têm como principal finalidade desenvolver, esclarecer e modificar conceitos e ideias, tendo em vista a formulação de problemas mais precisos ou hipóteses pesquisáveis para estudos posteriores".

O procedimento técnico adotado é o estudo de caso que consiste na investigação profunda e exaustiva de um ou poucos objetos, de maneira que permita seu amplo e detalhado conhecimento. Segundo Patton (2002), o propósito de um estudo de caso é reunir informações detalhadas e sistemáticas sobre um fenômeno.

Em relação a abordagem da pesquisa consiste em um estudo qualitativo, pois busca reduzir a distância entre a teoria e os dados, entre o contexto e a ação, usando a lógica da análise fenomenológica, isto é, da compreensão dos fenômenos pela sua descrição e interpretação, conforme Teixeira (2006, p.137) preconiza.

Foram realizadas entrevistas em profundidade com alunos dos cursos técnicos a distância do IF Goiano. O critério de escolha dos alunos entrevistados foi selecionar oito discentes de forma aleatória, entre os 107 polos do IF Goiano no estado de Goiás, conforme Tabela 1. 
Tabela 1 - Dados Demográficos dos Participantes

\begin{tabular}{|c|c|c|c|c|}
\hline Entrevistado & Gênero & Curso & Polo (GO) & $\begin{array}{l}\text { Faixa } \\
\text { Etária }\end{array}$ \\
\hline $\mathrm{E} 1$ & Feminino & Técnico em Administração & Palmeiras & $20-30$ \\
\hline E2 & Feminino & $\begin{array}{l}\text { Técnico em Segurança do } \\
\text { Trabalho }\end{array}$ & Morrinhos & $30-40$ \\
\hline E3 & Masculino & $\begin{array}{l}\text { Técnico em Segurança do } \\
\text { Trabalho }\end{array}$ & Firminópolis & $20-30$ \\
\hline E4 & Masculino & $\begin{array}{l}\text { Técnico em Segurança do } \\
\text { Trabalho }\end{array}$ & $\begin{array}{c}\text { São Luiz dos M. } \\
\text { Belos }\end{array}$ & $20-30$ \\
\hline E5 & Masculino & Técnico em Administração & Aragarças & $40-50$ \\
\hline E6 & Feminino & Técnico em Secretariado & Piranhas & $20-30$ \\
\hline E7 & Feminino & $\begin{array}{c}\text { Técnico em Segurança do } \\
\text { Trabalho }\end{array}$ & Caiapônia & $20-30$ \\
\hline E8 & Feminino & Técnico em Serviços Públicos & Doverlândia & $40-50$ \\
\hline
\end{tabular}

Fonte: Elaborado pelo autor (2016).

A verificação do rigor e precisão foi dada pelo princípio de saturação, ou amostragem teórica, considerando-se representativa a amostra quando nenhum dado novo vem contradizer as categorias estabelecidas. Isto é, a confiabilidade da pesquisa foi alcançada pela saturação das respostas, o instrumento epistemológico que diz que as observações deixam de ser necessárias quando nenhum novo exemplo permite ampliar o número de propriedades do objeto investigado (THIRY-CHERQUES, 2009, p. 26). Para que se atinja a saturação, é necessário que o protocolo de pesquisas contemple: 1. Um mínimo de oito observações, correspondentes ao mínimo das seis recomendadas, acrescidas das duas necessárias à confirmação da saturação; 2. Um máximo de 15 observações, correspondentes ao limite das duas recomendadas, acrescidas de $1 / 3$ de observações.

Tendo em vistas as questões colocadas aos entrevistados, que refletem os objetivos do estudo, uma análise preliminar buscou o momento em que novas informações agregam-se a conhecimento relevantes para a pesquisa, considerando cada um dos tópicos abordados e o conjunto dos entrevistados. Essa análise foi realizada na parte do pré-teste da pesquisa, com uma amostra reduzida e os participantes não fizeram parte da amostra final, quando efetivamente foram analisados os resultados coletados para a realização do estudo.

Ainda segundo Thiry-Cherques (2009) o critério de saturação pertence às esferas de validação objetiva e de inferência indutiva. É objetivamente 
válido na medida em que ele satisfaz as exigências lógicas de julgamento em um universo determinado. Tem legitimidade lógica, mas apresenta algumas limitações de ordem técnica. Aplica-se somente a casos específicos no âmbito das pesquisas de caráter qualitativo.

Segundo Fontanella, Ricas e Turato (2008, p. 20), a desnecessária representatividade estatística é um dos motivos pelos quais as amostras qualitativas são menores do que as necessárias nos estudos quantitativos, porém para os autores:

A necessidade de "fechamento" amostral exige do pesquisador a explicitação dos critérios para interromper a seleção de casos novos, tornando-os inteligíveis aos futuros leitores dos relatórios e norteadores do andamento prático dos procedimentos de captação.

Neste sentido, além do critério de saturação defendido por Therycherques (2009), destaque-se também a utilização de pré-categorias extraídas da escala SERVQUAL, SERPERF e HEdPERF, haja vista, é de certa forma previsível que as experiências vivenciadas quanto a qualidade dos serviços prestados pela Instituição para os participantes da amostra venham a se constituir ou enquadrar em uma das categorias de análise ou mesmo um objetivo específico do estudo.

$\mathrm{Na}$ elaboração do questionário semiestruturado para as entrevistas foram adaptados os atributos da escala SERVQUAL, SERVPERF e HEdPERF, para uma abordagem qualitativa. Para interpretação dos dados foi utilizada a Análise de Conteúdo, que segundo Bardin (1977), pode ser definida como:

Um conjunto de técnicas de análise de comunicações visando obter, por procedimentos sistemáticos e objetivos de descrição do conteúdo das mensagens, indicadores (quantitativos ou não) que possibilitam a inferência de conhecimentos relativos às condições de produção/recepção (variáveis inferidas), destas mensagens (BARDIN, 1977, p. 42). 


\section{RESULTADOS E DISCUSSÕES}

\subsection{Procedimento de Análise dos Resultados}

O processo de Análise de Conteúdo segundo Bardin (1977) é composto pelas fases: pré-análise, exploração do material e tratamento dos resultados, inferência e interpretação.

Seguindo os passos de Bardin (1997), na primeira fase da Análise de Conteúdo, pré-análise, foram organizadas todas as informações coletadas sobre os cursos técnicos a distância realizados entre pelo IF Goiano, a fim de subsidiar com informações para confecção do roteiro de entrevistas. Em seguida, foram organizadas as informações selecionadas, para manter um padrão, facilitando a análise posterior do material. Os temas que se repetem com muita frequência foram recortados "do texto em unidades comparáveis de categorização para análise temática e de modalidades de codificação para o registro dos dados (Bardin, 1979, p. 100).

A segunda fase constitui a exploração do material, que consiste essencialmente de operações de codificação que compreende a escolha de unidades de registro (recorte) e unidade de contexto (compreensão da unidade de registro), através de uma classificação semântica (temas).

O critério de categorização foi semântico e a priori, em que as categorias e seus respectivos indicadores são pré-determinados em função da busca a uma resposta específica do investigador. Neste caso, foram utilizados os atributos adaptados da Escala SERVQUAL, SERVPERF e HEdPERF original, que são a tangibilidade, confiabilidade, presteza, segurança, empatia, reputação, temas ou questões dos programas e compreensão.

A terceira e última fase consiste no tratamento dos resultados, inferência e interpretação. Nessa etapa ocorre a condensação e o destaque das informações para análise, culminando nas interpretações inferenciais; é o momento da intuição, análise reflexiva e crítica (BARDIN, 1977). Para cada uma das categorias foi produzido um texto síntese em que se expresse o conjunto de significados presentes nas diversas unidades de análise incluídas em cada uma delas. Nessa fase, a interpretação é essencial, que deve estar 
claramente relacionada aos dados coletados. Finalmente, sistematizar os resultados com os objetivos iniciais que é buscar uma resposta para o problema de pesquisa: quais os principais atributos para avaliar a qualidade institucional dos cursos técnicos a distância na perspectiva dos alunos?

A categorização inicial a priori que serviu como suporte da Análise de Conteúdo e baseou as entrevistas, apresenta os oito atributos da qualidade elencadas e adaptadas das teorias SERVQUAL; SERVPERF e HEdPERF, que são: Tangibilidade, Confiabilidade, Presteza, Segurança, Empatia, Reputação, Conteúdo do Programa e Compreensão. A partir das categorias a priori foram identificadas 18 subcategorias que emergira do texto pautadas nas narrativas dos entrevistados. O Quadro 6 ilustra o processo de formação da categoria intermediária.

Quadro 6 - Processo de Formação das Categorias Intermediárias

\begin{tabular}{|c|c|c|}
\hline Categorias a priori & Conceito Norteador & Subcategorias \\
\hline \multirow{3}{*}{ Tangibilidade } & $\begin{array}{l}\text { Demonstrando situação de satisfação } \\
\text { quanto a qualidade dos recursos } \\
\text { físicos e materiais disponibilizados } \\
\text { pela Instituição. }\end{array}$ & 1. Qualidade Satisfatória \\
\hline & $\begin{array}{l}\text { Demonstrando insatisfação apenas na } \\
\text { demora na entrega dos materiais } \\
\text { impressos. }\end{array}$ & $\begin{array}{l}\text { 2. Qualidade Insatisfatória } \\
\text { no Material Impresso }\end{array}$ \\
\hline & $\begin{array}{l}\text { Demonstrando insatisfação quanto a } \\
\text { qualidade dos recursos físicos e } \\
\text { materiais. }\end{array}$ & $\begin{array}{l}\text { 3. Qualidade Insatisfatória } \\
\text { quanto aos Recursos } \\
\text { Físicos e Materiais } \\
\end{array}$ \\
\hline \multirow{2}{*}{ Confiabilidade } & $\begin{array}{l}\text { Demonstrando segurança quanto as } \\
\text { transações com a Instituição. }\end{array}$ & \begin{tabular}{|l} 
4. Confiança na \\
Instituição
\end{tabular} \\
\hline & $\begin{array}{l}\text { Demonstrando insegurança quanto as } \\
\text { transações com a Instituição. }\end{array}$ & 5. Falhas de Confiança \\
\hline \multirow{3}{*}{ 3. Presteza } & $\begin{array}{l}\text { Demonstrando satisfação quanto a } \\
\text { prestação dos serviços oferecidos pela } \\
\text { Instituição. }\end{array}$ & $\begin{array}{l}\text { 6. Presteza na Prestação } \\
\text { de Serviços }\end{array}$ \\
\hline & $\begin{array}{l}\text { Demonstrando insatisfação apenas na } \\
\text { demora na prestação dos serviços } \\
\text { oferecidos pela Instituição. }\end{array}$ & $\begin{array}{l}\text { 7. Serviços Prestativos } \\
\text { Falhos }\end{array}$ \\
\hline & $\begin{array}{l}\text { Demonstrando insatisfação quanto a } \\
\text { prestação dos serviços oferecidos pela } \\
\text { Instituição. }\end{array}$ & $\begin{array}{l}\text { 8. Serviços Prestativos } \\
\text { Inadequados }\end{array}$ \\
\hline \multirow{2}{*}{ 4. Segurança } & $\begin{array}{l}\text { Demonstrando satisfação quanto a } \\
\text { segurança nas transações com a } \\
\text { Instituição. }\end{array}$ & $\begin{array}{l}\text { 9. Segurança e Confiança } \\
\text { na Instituição }\end{array}$ \\
\hline & $\begin{array}{l}\text { Demonstrando insatisfação quanto aos } \\
\text { problemas na plataforma de ensino. }\end{array}$ & $\begin{array}{l}10 . \quad \text { Insegurança } \\
\text { Instituição }\end{array}$ \\
\hline \multirow[t]{2}{*}{ 5. Empatia } & $\begin{array}{l}\text { Demonstrando satisfação quanto ao } \\
\text { atendimento oferecidos pelos } \\
\text { funcionários da Instituição. }\end{array}$ & 11. Empatia Satisfatória \\
\hline & $\begin{array}{l}\text { Demonstrando insatisfação relativo a } \\
\text { conflitos quanto a empatia. }\end{array}$ & 12. Empatia Insatisfatória \\
\hline
\end{tabular}




\begin{tabular}{|c|c|c|}
\hline Reputação & $\begin{array}{l}\text { Demonstrando satisfação quanto a } \\
\text { reputação em estudar em uma } \\
\text { Instituição Federal de Ensino. }\end{array}$ & 13. Reputação Favorável \\
\hline \multirow{3}{*}{$\begin{array}{l}\text { 7. Conteúdo do } \\
\text { Programa }\end{array}$} & $\begin{array}{l}\text { Demonstrando satisfação no programa } \\
\text { dos cursos oferecidos pela Instituição. }\end{array}$ & $\begin{array}{l}14 . \quad \text { Programa } \\
\text { Qualidade }\end{array}$ \\
\hline & $\begin{array}{l}\text { Demonstrando necessidade de } \\
\text { aprofundar os conhecimentos por parte } \\
\text { dos alunos. }\end{array}$ & $\begin{array}{|lr|}\text { 15. Qualidade } & \text { Razoável } \\
\text { do } & \text { Conteúdo } \\
\text { Programático } & \\
\end{array}$ \\
\hline & \begin{tabular}{|ll}
$\begin{array}{l}\text { Demonstrando insatisfação pelos } \\
\text { cursos não terem estágio. }\end{array}$ & \\
\end{tabular} & $\begin{array}{l}\text { 16. Falta de Estágio no } \\
\text { Conteúdo Programático }\end{array}$ \\
\hline \multirow[b]{2}{*}{ 8. Compreensão } & $\begin{array}{l}\text { Demonstrando satisfação quanto ao } \\
\text { atendimento personalizado oferecido } \\
\text { pela Instituição. }\end{array}$ & $\begin{array}{ll}17 . & \text { Compreensão } \\
\text { Adequada } & \end{array}$ \\
\hline & $\begin{array}{l}\text { Demonstrando insatisfação quanto ao } \\
\text { atendimento personalizado oferecido } \\
\text { pela Instituição. }\end{array}$ & $\begin{array}{l}\text { 18. Falhas } \\
\text { Compreensão. }\end{array}$ \\
\hline
\end{tabular}

Fonte: Elaborado pelo Autor (2016).

Após o processo de categorização é possível iniciar as inferências e relatar os resultados obtidos. O processo inclui extrair do texto transcrito as opiniões relacionadas as subcategorias correspondentes que por sua vez estão associadas as categorias a priori.

\subsection{Categoria - Tangibilidade}

Na primeira categoria tangibilidade, perguntou-se: Como você percebe e avalia os recursos físicos e materiais, como laboratórios, apostilas, móveis e formulários oferecidos pela Instituição aos alunos dos cursos técnicos a distância?

Fitzsimmons e Fitzsimmons (2010), define o fator tangibilidade aquele que representa as aparências das instalações físicas, equipamentos, funcionários e materiais de comunicação. Em sua maioria os relatos dos alunos consideram os recursos físicos e materiais de ótima qualidade, um ambiente agradável e acessível, com tudo funcionando adequadamente, demonstrando sua satisfação conforme relato dos entrevistados E4 e E8:

Olha até o momento que estamos está fazendo o curso está ótimo, a infraestrutura da escola está boa, as cadeiras, lugar de sentar, o Datashow que a professora passa o vídeo está ok, o vídeo não tem defeito, na parte que a gente está no curso não tem nada a reclamar (E4).

Para mim foi tudo certo, tudo em dia ... o ambiente aqui na escola é agradável, o ar condicionado funciona, a sala de aula é limpa, o equipamento tem funcionado correto, os 
únicos problemas são de falta de energia e internet de vez em quando, o ambiente é de ótima qualidade na escola (E8).

Porém, mesmo assim, foi identificada insatisfação quanto ao atraso na entrega do material impresso, ponto que foi mencionado por cinco entrevistados, conforme relato dos entrevistados E1 e E6:

Eu acho apenas que os livros ficaram a desejar, apesar de que eles explicaram no começo que teve um problema lá com a gráfica e não ia ser possível fornecer o material a tempo. Tirando isto as depois coisas eu considero que ficou bom. (E1).

Apesar do material está chegando um pouco atrasado, mas a qualidade é ótima. (E6).

Apenas no entrevistado E3 foi identificado insatisfação quanto a qualidade dos recursos físicos e materiais disponibilizados aos alunos, conforme relato.

Desde o começo do curso nós nunca tivemos uma sala específica para nossos estudos, a gente sempre teve uma sala improvisada com as cadeiras que tinham no local mesmo, não eram cadeiras as vezes confortáveis, a gente chega do trabalho cansado, no final da tarde as vezes não ficava legal, e os recursos a gente sempre tem que montar, tinha algumas vezes que não funcionavam, devido não ser o material apropriado para poder estar passando um curso a distância. (E3).

Conforme defendido por Deming (1990), a qualidade consiste na capacidade de satisfazer desejos. Esse conceito pode ser observado nas respostas dos alunos que em sua maioria demonstram a satisfação quanto a qualidade dos recursos físicos e materiais disponibilizados no curso.

\subsection{Categoria - Confiabilidade}

$\mathrm{Na}$ categoria confiabilidade foi realizada a seguinte pergunta: "Para você a Instituição sempre cumpre com sua palavra, obedecendo aos prazos acordados e executando os serviços sem erros para com os alunos? 
Para Parasuraman et al. (1985), a confiabilidade é referenciada como a execução de um serviço conforme combinado e prometido, com precisão, consistência e segurança.

Os dos alunos responderam que a Instituição inspira confiança e demonstra interesse em resolver os problemas e auxiliar os usuários, apesar de encontrar em três entrevistas evidências de descontentamento quanto a demora na resolução dos problemas apresentados conforme exposto nos relatos dos entrevistados E3 e E6:

Demora um pouquinho, a gente já teve problemas com provas e avaliações que nós fizemos, a gente fez aqui, fez um conjunto provas e avaliações e consta nota zerada até hoje, nós temos ainda algumas pendências aqui, estamos formando o quarto período agora e ainda temos pendência do primeiro período ainda que ainda não foram finalizadas por questão de sistema (E3).

O maior problema com os alunos são as notas que não são lançadas no portal no tempo hábil, dificultando o processo de avaliação e os alunos ficam preocupados em saber as suas notas. Foi o que aconteceu comigo, minha nota não foi colocada no portal então tive que recorrer a tutora presencial para resolver este problema. Mas foi resolvido dentro do prazo do semestre. (E6).

Contudo, observa-se que os alunos demonstram compreender as dificuldades que existem e confiam que a Instituição vai resolvê-los, conforme a fala dos entrevistados: "Às vezes demora um pouquinho" (E3), "Mas foi resolvido dentro do prazo do semestre" (E6), " De forma geral estão dispostos a resolver os problemas apesar de todas as dificuldades" (E7).

Segundo mencionado por Campos (1990), serviço de qualidade é aquele que atende perfeitamente de forma acessível, seguro, confiável e no tempo certo as necessidades do usuário. De acordo com está visão os cursos apresentam uma necessidade de melhoria no quesito confiabilidade junto a seus alunos, haja vista, para Parasuraman, Berry e Zeithaml (1985, 1988), a confiabilidade é a habilidade de cumprir o que foi prometido com exatidão, 0 que não se observa na totalidade dos casos. Identificou-se ainda uma repetição considerável da palavra problema 0 que evidencia 0 descontentamento dos discentes quanto ao prazo para resolução das demandas dos alunos. 


\subsection{Categoria - Responsividade/presteza}

A categoria responsividade/presteza está relacionada a seguinte pergunta: Como você considera os serviços de atendimento aos alunos por parte dos funcionários e professores?

Para Parasuraman, Zeithaml e Berry (1985), responsividade/presteza caracterizam a boa vontade em ajudar os usuários e prestar serviços prontamente.

A opinião dos alunos entrevistados indica uma satisfação quanto à capacidade para atender os usuários e fornecer o serviço prontamente, demonstrando flexibilidade e habilidade para adaptar o serviço às necessidades do usuário, conforme relato do aluno $\mathrm{E} 1$ :

Os tutores são ótimos aqui, toda a vez que a gente precisa deles, eles então sempre presentes, em tudo que a gente precisa eles ajudam sempre, são muito bons mesmo em tudo que a gente precisa, a agilidade deles, a eficácia, tudo muito bons. $\mathrm{Eu}$ estou satisfeito com $\mathrm{O}$ atendimento deles, principalmente os tutores presenciais. (E1).

$\mathrm{Na}$ visão de Juran (1974), o nível de satisfação alcançado por um determinado serviço no atendimento aos objetivos do usuário, durante o seu uso, é chamado de adequação ao uso e que pode ser aplicável a qualquer tipo de bem ou serviço. Segundo este conceito, pode-se dizer que em relação ao responsividade/presteza os alunos dos cursos técnicos a distância realizados pelo IF Goiano estão satisfeitos.

Apenas um aluno destacou a demora no atendimento e considerou falho $\mathrm{o}$ atendimento, conforme relato do entrevistado E7:

Neste semestre eu tive um pouco de dificuldade na questão de responder as perguntas na plataforma, eu não sei se é uma questão de momento, as vezes fica sem responder, eu tenho até perguntas que não foram respondidas, eu não sei se é problema que está acontecendo na rede, antigamente este problema não existia (E7). 
Dos oitos alunos que responderam as entrevistas, seis repetiram várias vezes a palavra "sempre", conforme os seguintes relatos: "eles estão sempre presentes"; "sempre eles estão dispostos a ajudar"; "os professores presenciais...eles são sempre prestativos"; "tentando sempre resolver os problemas"; "ela sempre procura a respostas e de imediato vem a solução"; "mas sempre estão dispostos a nós atender". O que demonstra a disposição da Instituição em resolver os problemas apresentados pelos alunos.

\subsection{Categoria - Garantia/segurança}

$\mathrm{Na}$ categoria garantia/segurança que se trata da competência e cortesia estendida aos usuários e a segurança fornecida através das operações, está relacionada a seguinte pergunta da entrevista: Em seu ponto de vista os funcionários e professores (presenciais e a distância) da Instituição inspiram confiança no atendimento aos alunos dos cursos à distância?

Para Kotler (2000) esta categoria avalia a maneira como a organização se apresenta o conhecimento dos produtos oferecidos, a cortesia dos funcionários e, principalmente a habilidade destes funcionários em inspirar confiança e responsabilidade para o cliente que contrata os serviços da Instituição. A categoria tem ainda como característica a faculdade dos usuários dos serviços acreditarem na organização e sentirem-se seguros em suas transações. Prevalece na resposta da questão por parte dos alunos um sentimento de segurança, confiança, competência e compromisso em relação a Instituição. Tal constatação pode ser observada em vários relatos:

Sim, possuem total capacidade e transmitem segurança, na maioria das nossas dúvidas, as respostas são sempre de acordo com aquilo que a gente pergunta, dentro daquilo que a gente está estudando, mostrando sabedoria aquilo que estão fazendo que e transmissão do conhecimento aos alunos (E4).

Eu tenho confiança, desde o primeiro curso que eu fiz, eles têm cumprido certinho tudo o que eles combinam comigo (E8). 
O único discente que destoou quanto a esta categoria foi 0 entrevistado E7 que destaca certa dificuldade por parte da Instituição em cumprir este quesito:

O problema é a plataforma que não tem sido respondida. Você faz perguntas no chat da plataforma não tem sido respondida.

Os demais entrevistados informaram que a Instituição inspira confiança, demonstrando segurança nas transações com os alunos, cordialidade por partes dos funcionários e conhecimento profissional para responder as perguntas dos usuários.

Paladini (1994), considera um serviço de qualidade corretamente definido como aquele que prioriza o consumidor. Isto mostra que a qualidade é mais do que simples estratégia ou técnica é, antes, uma questão de decisão que reflete em políticas de funcionamento da organização.

\subsection{Categoria - Empatia}

A categoria empatia está relacionada a seguinte pergunta da entrevista: Como você caracteriza a conduta de funcionários e professores no momento do atendimento ao aluno? Nesta categoria observa-se uma concordância entre os alunos que consideram servidores e funcionários da Instituição (tutores presencias e a distância) como educados, atenciosos, prestativos e ágeis no atendimento.

Os autores Parasuraman, Zeithaml e Berry (1985) caracterizam a empatia como a atenção e o carinho individualizado com que são atendidos os usuários. Os autores ainda destacam a empatia como a capacidade que o atendente tem de se colocar na situação do outro, com boa comunicação e cortesia. Estas características e atributos são encontrados em vários momentos das entrevistas, como relato dos entrevistados E2, E4, E5 e E8:

Eles são educados, eles são muito prestativos, eles nos deixam a vontade, eu vejo os professores hoje até pelo nome, como se eu estivesse com eles todos os dias, eu entro na plataforma e eu não vejo distância, entre eu e os professores. (E2). 
Eles sempre respondem com bastante educação, sempre prestativos nas respostas, no que diz respeito a nossas dúvidas são sempre respondidas (E4).

$O$ atendimento é muito bom, eu gosto do atendimento da Instituição porque os coordenadores e tutores presenciais e a distância são atenciosos, dão toda a atenção que os alunos precisão. (E5).

A gente vê que eles têm boa vontade com a gente, o pessoal aqui do polo ajuda, olham para ver se está tudo certo na plataforma, se tiver algum problema elas tiram um tempo para atender a gente. (E8).

Contudo, mesmo considerando satisfatório esta categoria, um aluno comentou sobre alguns atritos apresentado durante o curso. Os atritos apresentados ficaram por conta do entrevistado E1 que mais uma vez destacou a demora na entrega do material impresso, conforme exposto:

A Instituição responde para a gente muito rápido, mas em questão assim de, quando a gente precisa do material mesmo e o que está ficando a desejar, causando um certo atrito com a insistência por parte dos alunos na busca pelo material, o que está causando um certo atraso no ensino, não está fluindo. E o que está causando mais problema, o material. (E1).

Segundo Kotler, Hayes e Bloom (2002, p. 58), "Todo mundo gosta de ser tratado como alguém importante. A capacidade de fazer cada cliente se sentir especial e importante constitui o ponto crucial para estabelecer empatia". Pelos relatos dos entrevistados observa-se que essa categoria empatia apresenta um nível de satisfação considerável por parte dos alunos, e que a Instituição preza por responder os usuários de seus serviços de forma educada e prestativa.

\subsection{Categoria - Reputação}

A categoria reputação está presente na seguinte pergunta da entrevista: Na sua opinião a realização de cursos em uma Instituição Pública Federal de Ensino contribui para o conceito do curso, refletindo na reputação do certificado?

De acordo com Firdaus (2006) no atributo reputação da Instituição são levantados aspectos relativos sua imagem e localização, os conceitos percebidos dos programas oferecidos, os recursos acadêmicos 
disponibilizados, à empregabilidade ou laboralidade dos cursos oferecidos aos discentes, etc.

Esses aspectos são levantados pelos entrevistados em vários momentos das entrevistas conforme os relatos dos entrevistados abaixo:

Contribui sim, e uma Instituição de peso, vale a pena ter feito o curso e lá na frente, vai ser reconhecido. Dependendo do local aonde vai se trabalhar, a realização do curso em uma Instituição pública tem um peso sim (E3).

Contribui significativo, mesmo sendo um curso a distância, quando eu falo que estou estudando Técnico de Segurança do Trabalho no IF a gente nota um diferencial, o IF é uma Instituição bem conhecida em Goiás é possui credibilidade, já é uma referência em educação pública e contribui em muito na hora de conseguir um emprego (E4).

Com certeza, o Instituto Federal ele é uma Instituição de muito valor, quando você fala para uma pessoa que está fazendo um curso no Instituto Federal Goiano muda até a visão da pessoa, as vezes a forma de olha (E7).

Nesta categoria observa-se uma unanimidade entre os entrevistados que consideram que o curso possui credibilidade, qualidade e reputação junto à comunidade e o mercado de trabalho. A satisfação quanto a reputação da Instituição está presente em vários comentários transcritos das entrevista, tais como: " bastante porque só da gente está estudando em uma IF já te dá outro ponto de vista"; "só de ser uma IF já causa uma forte procura", "todo mundo acha interessante, porque tem nome"; "é uma diferença muito grande"; "é uma Instituição de peso"; "uma Instituição Pública tem um peso"; "a apresentação de um certificado de uma Instituição Pública tem um peso sim"; "quando eu falo que estou estudando Técnico em Segurança do Trabalho no IF a gente nota um diferencial"; "o IF é uma Instituição bem conhecida em Goiás e possui credibilidade", "já é uma referência em educação pública", "contribuir em muito na hora de conseguir um emprego"; o IF é de muita qualidade, e muito respeito com o curso que ela está prestando a comunidade"; "é outra qualidade, quando eu falo que sou formado pelo IF Goiano"; "ter uma formação federal as portas se abrem para a gente"; "é muito importante a reputação em uma Instituição Federal"; "eu acredito que sim, eu acho que vai fazer diferença quando eu for para o mercado de trabalho". 
Os comentários contribuem para inferir que a os discentes consideram que os cursos técnicos a distância.

\subsection{Categoria - Conteúdo Programático}

A penúltima categoria destaca o conteúdo programático dos cursos e está contemplada na seguinte pergunta: Quanto ao conteúdo programático do curso, você considera que o programa está de acordo com um nível de satisfatório exigido pelo mercado de trabalho? Segundo Firdaus (2006) esta categoria corresponde a grade dos cursos que deve oferecer uma gama extensiva e respeitável de programas e conteúdos flexíveis a fim de favorecer o estímulo à pesquisa científica, ao crescimento do conhecimento e da vida profissional.

$\mathrm{Da}$ análise das respostas das entrevistas referente a pergunta encontramos o mais alto índice de divergências, enquanto $60 \%$ considera que o curso apresenta conhecimentos e qualificação necessária exigida pelo mercado, os $40 \%$ restante já julga que o curso não apresenta todos os conhecimentos necessários a um futuro profissional técnico, exigindo para isso uma melhor especialização em sua área de atuação.

Os entrevistados E1 e E2 consideram que o curso possui todos os atributos satisfatórios necessários e exigidos pelo mercado de trabalho, conforme os relatos abaixo:

O que a gente aprende aqui nas aulas e bem do nosso dia a dia, eu uso muito no trabalho, tudo que eu aprendo no curso de administração e muito, mas muito mesmo usado, na teoria a gente põe na prática, sempre. Eu considero que o conhecimento adquirido neste curso vai me ajudar muito na minha vida profissional (E1).

Eu acho que o curso transmite mais que o básico, eu acho que o profissional sai formado do Instituto Federal hoje eu acho que eles saem pronto para o mercado de trabalho, e aí depende de cada um, porque a gente tem um material de apoio muito bom (E2).

Já os entrevistados E3 julga que o curso transmite apenas o básico, exigindo de cada futuro profissional um aprofundamento, uma especialização em sua área de trabalho específica, conforme relatos abaixo: 
Vou sair do curso com uma base técnica para trabalho..., porém depois cada um tem que se dedicar, aprofundar os estudos na área de atuação, na área que se dedica mais. (E3).

O entrevistado E6 destacou um aspecto relevante sobre os cursos técnicos a distância do IF Goiano, que é a não obrigatoriedade de estágio supervisionado, conforme relato abaixo:

Sim, a única reclamação que eu tenho e a falta de estágio, não é obrigatório, você pode até fazer o estágio, tem o termo de estágio, mas não tem a obrigação de fazer, por ser um curso técnico é muito importante o conhecimento da parte prática (E6).

Uma leitura do texto transcrito depreende-se que os discentes têm a consciência da necessidade de aprofundar os estudos, haja vista, segundo os alunos o curso técnico a distância não abordar todos os conhecimentos necessários para desempenho com segurança no mercado de trabalho.

\subsection{Categoria - Compreensão}

A última categoria analisada, compreensão, está relacionada a seguinte pergunta da entrevista: Você identifica que a Instituição de Ensino demonstra preocupação em atender as necessidades específicas de cada aluno, como aconselhamento ou serviço de saúde, ou outra necessidade especial qualquer?

Para Firdaus (2005) a compreensão trata-se de itens relacionados à percepção das necessidades dos alunos em termos de aconselhamento e serviços. De maneira geral esse fator avalia se a Instituição tem um departamento exclusivo para ouvir as necessidades e anseios de seus alunos, uma ouvidoria ou instrumento semelhante.

Sete dos oito entrevistados consideram que o curso apresenta um atendimento individualizado com qualidade. A entrevistada E2 vai além ao destacar a preocupação com um comportamento humanizado desempenhado pela Instituição, conforme relato: 
A Instituição tem essa preocupação sim, eu falo que o atendimento e muito humanizado..., eu já presenciei vários casos de alunos que deixaram de vir, mas chegou no tutor e explicou o que aconteceu e com a falta justificada e o aluno não fica no prejuízo na matéria (E2).

Paladini (1994) destaca que a qualidade corretamente definida é aquela que prioriza o consumidor. Isto mostra que a qualidade é mais do que uma simples metodologia estratégica ou técnicas de atendimento é, antes, uma questão de decisão que reflete em políticas de funcionamento da organização. Neste sentido observa-se que a Instituição está preocupada em atender as necessidades e anseios de seus discentes de forma especial e com qualidade.

Apenas uma aluna destaca que as dificuldades financeiras que o país está passando prejudica no atendimento da Instituição, conforme relato da entrevistada E7:

Eu acho que a questão do momento que estamos passando, as vezes pode ter alguma dificuldade....as vezes eles querem trabalhar, mas os recursos estão escassos, não tem verba necessária para acompanhar de forma satisfatória como um todo. (E7).

Contudo, mesmo assim, ela defende a Instituição na parte final de sua resposta ao comentar:

Mas a gente nota que eles têm se prestado, eles estão sempre junto para atender a gente. Sempre que há uma necessidade eles estão sempre resolvendo. (E7).

O que demonstra que a Instituição mesmo diante de dificuldades procura atender as necessidades especiais de seus alunos, compreendendo suas necessidades e desejos, procurando oferecer soluções para as necessidades específicas, objetivando atender as necessidades e de seus alunos.

\subsection{Análise Global dos Dados}

Objetivando apresentar uma síntese das análises dos resultados das entrevistas, apresentando as categorias principais e as subcategorias extraídas, levando em consideração como categorias principais os atributos 
adaptados de qualidade em serviços à luz das teorias SERVQUAL, SERVPERF e HEdPERF, foi elaborado um quadro comparativo, ilustrando os principais resultados da pesquisa.

Quadro 7 - Síntese dos Principais Resultados da Pesquisa

\begin{tabular}{|c|c|c|}
\hline Categoria & Subcategorias & Resultados \\
\hline 1. Tangibilidade & $\begin{array}{ll}\text { - } & \text { Qualidade } \\
\text { Satisfatória } \\
\text { - } \quad \text { Qualidade } \\
\text { Insatisfatória no } \\
\text { Material Impresso } \\
\text { - } \quad \text { Qualidade } \\
\text { Insatisfatória dos } \\
\text { Recursos Físicos e } \\
\text { Materiais }\end{array}$ & $\begin{array}{l}\text { A maioria os alunos estão } \\
\text { satisfeitos com os recursos } \\
\text { físicos e materiais oferecidos } \\
\text { pela Instituição. Quatro alunos } \\
\text { destacaram o atraso na entrega } \\
\text { das apostilas o que foi } \\
\text { considerado prejudicial para o } \\
\text { desenvolvimento dos estudos. } \\
\text { Apenas um aluno classificou } \\
\text { como insatisfatório os recursos } \\
\text { físicos e materiais oferecidos } \\
\text { pela Instituição. }\end{array}$ \\
\hline 2. Confiabilidade & $\begin{array}{l}\text { - Instituição confiável } \\
\text { - } \quad \text { Falhas de confiança }\end{array}$ & $\begin{array}{l}\text { A maioria dos alunos considera } \\
\text { que a Instituição é confiável. } \\
\text { Três alunos destacaram a falta } \\
\text { de confiança ao mencionar } \\
\text { alguns problemas e dificuldades } \\
\text { que afeta o nível de confiança na } \\
\text { Instituição. }\end{array}$ \\
\hline 3. Presteza & $\begin{array}{ll}\text { - } & \text { Presteza na } \\
& \text { prestação de } \\
& \text { serviços } \\
\text { - } & \text { Serviços } \\
& \text { Prestativos falhos } \\
\text { - } & \text { Serviços } \\
& \text { Prestativos } \\
& \text { inadequados }\end{array}$ & $\begin{array}{l}\text { Seis alunos destacaram como } \\
\text { de ótima qualidade os serviços } \\
\text { apresentados pela Instituição, } \\
\text { apenas um aluno destacou a } \\
\text { demora na resposta dos } \\
\text { problemas apresentados e outro } \\
\text { destacou que existe uma } \\
\text { dificuldade na resposta, sendo } \\
\text { que em certas situações eles } \\
\text { nem respondem. }\end{array}$ \\
\hline 4. Segurança & $\begin{array}{llr}\text { - } & \text { Segurança } & \text { e } \\
\text { confiança } & \text { na } \\
\text { Instituição } & \\
\text { - } & \text { Insegurança } & \text { na } \\
\text { Instituição } & \end{array}$ & $\begin{array}{l}\text { A segurança foi muito bem } \\
\text { avaliada pelos alunos, sendo } \\
\text { que apenas um apresentou } \\
\text { insatisfação quanto a segurança } \\
\text { da Instituição, sobretudo quanto } \\
\text { a plataforma que apresentado } \\
\text { problemas, principalmente no } \\
\text { chat. }\end{array}$ \\
\hline \multirow[t]{2}{*}{ 5. Empatia } & $\begin{array}{l}\text { - Empatia satisfatória } \\
\text { - Empatia } \\
\text { insatisfatória }\end{array}$ & $\begin{array}{l}\text { A empatia foi outro item muito } \\
\text { bem avaliado pelos alunos, que } \\
\text { classificou os colaboradores } \\
\text { cordiais, educados, prestativos e } \\
\text { gentis, alguns chegaram a } \\
\text { considerar perfeito, bom e } \\
\text { atencioso. Um aluno destacou } \\
\text { que houve um certo atrito com } \\
\text { relação a queixas na demora do } \\
\text { material, o que segundo ele } \\
\text { causou um atraso no ensino. }\end{array}$ \\
\hline & - Reputação & $\begin{array}{l}\text { A reputação foi a categoria mais } \\
\text { bem avaliada pelos alunos. }\end{array}$ \\
\hline
\end{tabular}




\begin{tabular}{|c|c|c|c|}
\hline & Reputação & favorável & $\begin{array}{l}\text { Todos destacaram que o curso } \\
\text { possui reconhecimento, respeito, } \\
\text { diferencial e credibilidade junto } \\
\text { ao mercado de trabalho. }\end{array}$ \\
\hline 7. & $\begin{array}{l}\text { Temas } \\
\text { Questões } \\
\text { Programas }\end{array}$ & $\begin{array}{l}\text { - } \begin{array}{l}\text { Programa de } \\
\text { qualidade }\end{array} \\
\text { - } \text { Qualidade razoável } \\
\text { do conteúdo } \\
\text { programático } \\
\text { - Falta de estágio no } \\
\text { conteúdo } \\
\text { programático }\end{array}$ & $\begin{array}{l}\text { Foi a categoria que apresentou } \\
\text { maior divergência observado nas } \\
\text { entrevistas dos alunos. Uma } \\
\text { pequena maioria considera de } \\
\text { qualidade o conteúdo } \\
\text { programático dos cursos, } \\
\text { enquanto a outra parte considera } \\
\text { que o curso apresenta apenas o } \\
\text { básico, necessitando de um } \\
\text { aprofundamento dos estudos } \\
\text { após sua conclusão. }\end{array}$ \\
\hline & Compreensão & $\begin{array}{l}\text { - Compreensão } \\
\text { adequada } \\
\text { - Falta } \\
\text { compreensão }\end{array}$ & $\begin{array}{l}\text { Sete alunos consideraram que a } \\
\text { Instituição apresenta um ótimo } \\
\text { desempenho neste item. Uma } \\
\text { aluna chegou a destacar o } \\
\text { atendimento humanizado e a } \\
\text { preocupação por parte do } \\
\text { Instituto em atender as } \\
\text { necessidades específica dos } \\
\text { alunos. Apenas uma aluna } \\
\text { destacou que por falta de } \\
\text { recursos financeiro, proveniente } \\
\text { da atual situação econômica do } \\
\text { país, a Instituição deixa de fazer } \\
\text { um acompanhamento melhor } \\
\text { para com os alunos. }\end{array}$ \\
\hline
\end{tabular}

Fonte: Elaborado pelo Autor (2016).

Pela análise e observação do Quadro 7, infere-se que os entrevistados estão satisfeitos com a qualidade dos serviços oferecidos nos cursos técnicos a distância ofertados pelo IF Goiano, em relação aos atributos tangibilidade, confiança, presteza, segurança, empatia, reputação, conteúdo programático e compreensão.

\section{CONSIDERAÇÕES FINAIS}

Estudos sobre a avaliação da qualidade de serviços trazem implicações que podem contribuir para a melhoria da gestão. No setor público, observar a qualidade dos serviços é fundamental e deve ser cada vez mais valorizado, tendo em vista que são os maiores prestadores de serviços para uma sociedade que dela depende. Nesse sentido esta pesquisa apresentou o seguinte problema: quais os principais atributos para avaliar a qualidade dos cursos técnicos a distância na perspectiva dos alunos? Para 
tanto a pesquisa utiliza os atributos de qualidade apresentados pelas metodologias SERVQUAL, SERVPERF e HEdPERF.

Inicialmente foram adaptadas oito categorias (atributos de qualidade) principais: tangibilidade, confiabilidade, presteza, segurança, empatia, reputação, conteúdo do programa e compreensão, presentes no modelo SERVQUAL, SERVPERF e HEdPERF, e posteriormente foram extraídas do texto transcrito 18 subcategorias: 1. Qualidade Satisfatória, 2. Qualidade Insatisfatória no Material Impresso, 3. Qualidade Insatisfatória quanto aos Recursos Físicos e Materiais, 4. Confiança na Instituição, 5. Falhas de Confiança, 6. Presteza na Prestação de Serviços, 7. Serviços Prestativos Falhos, 8. Serviços Prestativos Inadequados, 9. Segurança e Confiança na Instituição, 10. Insegurança na Instituição, 11. Empatia Satisfatória, 12. Empatia Insatisfatória, 13. Reputação Favorável, 14. Programa de Qualidade, 15. Qualidade Razoável do Conteúdo Programático, 16. Falta de Estágio no Conteúdo Programático, 17. Compreensão Adequada, e 18. Falhas na Compreensão.

A tangibilidade apresentou um alto índice de insatisfação em relação ao material impresso, especificamente quanto as apostilas que não foram disponibilizadas a tempo para os alunos. Outros fatores também contribuíram para considerar este atributo como a mais insatisfatória pelos entrevistados, tais como: local específico para estudo, salas improvisadas, etc.

$\mathrm{Na}$ categoria confiança observa-se um nível satisfatório. Os pontos considerados de falhas de confiança estão relacionados a demora na entrega do material impresso, o que levou os entrevistados a desconfiar da Instituição em cumprir com o prometido no início do curso, que era entregar as apostilas impressas de todas as disciplinas, o que acabou não acontecendo.

Em relação a categoria presteza também foi identificado um alto nível de satisfação, apesar do relato de alguns entrevistados destacarem a demora nas respostas por parte dos tutores a distância.

A categoria segurança os entrevistados demonstraram em seus relatos ter confiança na Instituição e descrevendo possui experiência, conhecimento e competência para responder os questionamentos e transmitindo segurança em todas as suas transações. 
Na empatia o nível de satisfação foi bem avaliado, o único fato identificado nas entrevistas foi a insistência por parte dos alunos na cobrança das apostilas que não chegaram, contudo, o mesmo aluno que destacou este fato, informou que no mais o pessoal é muito cordial e educado.

Em relação a reputação foi o mais bem avaliada pelos alunos que consideram de fundamental importância para o seu futuro profissional a realização de um curso profissionalizante em uma Instituição pública. Todos os alunos entrevistados destacaram o diferencial do curso, sua credibilidade e reputação no mercado de trabalho.

Já a categoria: conteúdo programático do curso, verificou-se uma significativa divergência dos alunos, sendo que cinco entrevistados consideram o material bom e de acordo com o exigido pelo mercado, os outros três entrevistados consideram que o material possui apenas o básico, exigindo do futuro profissional um aprofundamento dos estudos em sua área específica de atuação.

Por último a categoria compreensão foi muito bem avaliada pelos entrevistados que destacaram até um atendimento individual e humanizado. Verifica-se que há uma preocupação em atender as necessidades específicas dos estudantes em termos de aconselhamento e na sua formação.

Conclui-se que as metodologias SERVQUAL, SERVPERF e HEdPERF constituem uma alternativa viável para avaliação da qualidade dos serviços educacionais e que os atributos de qualidade identificados contribuem para apontar lacunas de qualidade em serviços educacionais, os quais devem ser monitorados para assegurar uma prestação de serviços de qualidade aos discentes dos cursos técnicos a distância realizados pela IF Goiano em parceria com a Rede e-Tec.

Recomenda-se em termos de investigações futuras a respeito do tema proposto, replicar a pesquisa em outras instituições públicas através de metodologias e técnicas de exploração mais aprofundada, utilizando levantamentos quantitativos para justificar os resultados da pesquisa qualitativa e evidenciar as devidas relações dos resultados encontrados.

Sugere-se ainda a continuidade do presente estudo por meio de uma pesquisa longitudinal, com objetivo de identificar possíveis melhorias e 
disfunções na qualidade ao longo dos cursos, o que contribui para detectar as fontes dos problemas na qualidade dos serviços e assim buscar sua melhoria, fatores fundamentais para o sucesso de uma Instituição de ensino.

\section{REFERÊNCIAS}

ANDERSON, E.W.; FORNELL, C.; LEHMANN, D.R. Customer Satisfaction, Market Share and Profitability: Findings from Sweeden Journal of Marketing. v. 58, n. 2, p. 53-66, jul. 1994.

ANDRETTI, F. Análise do processo de entrega de serviços com base em modelo de correlação entre percepção e indicadores do processo. 2006. Dissertação (Mestrado Engenharia Industrial). PUC. Rio de Janeiro, 2006.

BABAKUS, E.; BOLLER, G. W. An empirical assessment of the SERVQUAL scale. Journal of Business Research, v. 24, n. 2, p. 253-68, 1992.

BARDIN, L. Análise de conteúdo. Lisboa: Edições 70, 1977.

BEISIEGEL, C. R. A qualidade do ensino na escola pública. Brasília: Liber Livro, 2005.

BRASIL. Lei no 13.005, de 25 de junho de 2014. Aprova o Plano Nacional de Educação - PNE e dá outras providências. Diário Oficial da União. Brasília, 26 de junho de 2014.

CAMPOS, V. F. Gerência da qualidade total: estratégia para aumentar competitividade da empresa brasileira. Belo Horizonte: Fundação Christiano Ottoni, 1990.

CARMAN, J. M. Consumer perceptions of service quality: an assessment of the ServQual dimensions. Journal of Retailing, v. 66, n. 1, p. 33-35, 1990.

CARVALHO, M. C. Avaliação da qualidade percebida nas instituições de ensino técnico: um estudo no município de Lavras. 2009. 123f. Dissertação (Mestrado em Administração) - Universidade Federal de Lavras, Lavras, 2009.

CHAGAS, L. R. Mapeamento da percepção dos alunos de uma escola de idiomas: uma adaptação do modelo HEdPERF. 2010. 108f. Dissertação (Mestrado em Sistemas de Gestão), Universidade Federal Fluminense, Niterói, 2010.

COELHO, C. D. dos A. Avaliação da qualidade percebida em serviços: aplicação em um colégio privado de ensino fundamental e médio. Florianópolis. 2004. 179f. Dissertação (Mestrado em Engenharia de Produção) - Universidade Federal de Santa Catarina, Florianópolis, 2004. 
CRONIN JR, J; TAYLOR, S. A. Measuring service quality: a reexamination and extension. Journal of Marketing, v. 56, n. 3, p. 55-68, 1992.

CROSBY, P. B. Quality is free: the art of making quality certain. New York: Mc Graw-Hill, 1979.

DEMING, W. E. Qualidade: a revolução da administração. Rio de Janeiro: Saraiva, 1990.

DI GIACOMO, W. A. O New Public Management no Canadá e a gestão pública contemporânea. Revista Interfaces Brasil/Canadá, Porto Alegre, v. 5, n. 5, p. 155-170, 2005.

DINSDALE, G.; MARSON, D. B.; SCHMIDT, F. \& STRICKLAND, T., 2000. Metodologia para Medir a Satisfação do Usuário no Canadá: Desfazendo Mitos e Redesenhando Roteiros. Cadernos ENAP, Brasília; nº 20, 2000.

DOURADO, L.F.; OLIVEIRA, J. F. A qualidade da educação: perspectivas e desafios. Caderno Cedes, Campinas, v. 29, n. 78, p. 201-215, mai./ago. 2009.

FEIGENBAUN, A. V. Total quality control. 3. ed. New York: Mc Graw Hill, 1991.

FINN, D. W.; LAMB, C. W. An evaluation of the Servqual scales in retail setting. Advances in Consumer Research, v. 18, p. 483-490, 1991.

FERREIRA, R. A.; TENÓRIO, R. M. Avaliação Educacional e Indicadores de Qualidade: um enfoque epistemológico e metodológico. TENÓRIO, R. M.; LOPES, U. M. (Org.). In: Avaliação e Gestão: Teorias e Práticas. Salvador: EDUFBA, p. 143-181, 2010.

FIRDAUS, A. HEdPERF versus SERVPERF: The quest for ideal measuring instrument of service quality in higher education sector. Quality Assurance in Education, v. 13, n. 4, p. 305-328, 2005.

The development of HEdPERF: a new measuring instrument of service quality for the higher education sector. International Journal of Consumer Studies, v. 30, n. 6, p. 569-581, nov. 2006.

FITZSIMMONS, J. A.; FITZSIMMONS, M. J. Administração de serviços: operações, estratégia e tecnologia de informação. 6. ed. Porto Alegre: Bookman, 2010.

FONTANELLA, B. J. B; RICAS, J.; TURATO, E. R. Amostragem por saturação em pesquisas qualitativas em saúde: contribuições teóricas. Cadernos de Saúde Pública, Rio de Janeiro, v. 24, n. 1, p. 17-27, 2008. 
HENNIG-THURAU, T; LANGER, M. F.; HANSEN, U. Modeling and Managing Student Loyalty: An Approach Based on the Concept of Relationship Quality. Journal of Service Research, v. 3, n. 4, p. 331-344, 2001.

HOFFMAN, K. D; BATESON, J. E. G. Princípios de Marketing de Serviços: conceitos, estratégias e casos. 2. ed. São Paulo: Thomson Learning, 2003.

GIL, A. C. Métodos e Técnicas de Pesquisa Social. 6. ed. São Paulo: Atlas, 2008.

GRÖNROOS, C. A. Marketing: Gerenciamento de Serviços - A Competição por Serviços na Hora da Verdade. Rio de Janeiro: Campus, 1995.

GUMMESSON, E. Service management: an evaluation and the future. International Journal of Service Industry Management, v 5, n. 1, p. 77-96, 1994.

ISHIKAWA, K. TQC: Total Quality Control: estratégia e administração da qualidade. São Paulo: IM \& C Internacional Sistemas Educativos, 1986.

JOSEPH, M.; JOSEPH, B. Service quality in education: a student perspective. Quality Assurance in Education, Bradford, v. 5, n. 1, p. 15-21, 1997.

JURAN, J. M. (ed.). Quality control handbook. 3. ed. New York. McGrawHill, 1974.

KLAUCK, G. A. C. Indicadores de qualidade de ensino: estudo em escola destaque no Ideb. 2012. 187f. Dissertação (Mestrado em Educação) Universidade Federal da Grande Dourados, Dourados-MS. 2012.

KOTLER, P.; HAYES, T.; BLOOM, P. Marketing de Serviços profissionais. 2. ed. São Paulo: Manole, 2004

KOTLER, P. Administração de Marketing. 10ª ed. São Paulo: Prentice Hall, 2000.

KOTLER, P.; KELLER, K. L. Administração de marketing. 12. ed. São Paulo: Pearson Prentice Hall, 2006.

LOVELOCK, C.; WIRTZ, J. Marketing de serviços: pessoas, tecnologia e resultados. 5. ed. São Paulo: Pearson Prentice Hall, 2006.

LOVELOCK, C.; WRIGHT, Lauren. Serviços: marketing e gestão. São Paulo: Saraiva, 2002.

MIGUEL, P. A. C.; SALOMI, G. E. Uma revisão dos modelos para medição da qualidade de serviços. Revista Produção, v. 14, n. 1, p. 12-30, 2004.

OLIVEIRA, J. F. A função social da educação e da escola pública: tensões, desafios e perspectivas. In: FERREIRA, E. B.; OLIVEIRA, D. A. (Org.) Crise 
da escola e políticas educativas. Belo Horizonte: Autêntica Editora, p. 237252, 2009.

OLIVEIRA, R. P.; ARAÚJO, G. C. Qualidade do ensino: uma nova dimensão da luta pelo direito à educação. Revista Brasileira de Educação. n. 28, p. 524, jan./fev./mar./abr. 2005.

OLIVER, R. L. A cognitive model of the antecedents and consequences of satisfaction Decisions. Journal of Marketing Research, vol. 17, n. 11, p. 460-469, 1980.

Cognitive, affective, and attribute bases of the satisfaction response. Journal of Consumer Research, p. 418-430, dez. 1993.

PALADINI, E. P. Qualidade Total na prática: Implantação e avaliação de sistemas de qualidade total. São Paulo: Atlas, 1994.

PATTON, M. G. Qualitative Research and Evaluation Methods, 3. ed. Thousand Oaks, CA: Sage, 2002.

PARASURAMAN, A., ZEITHAML, V. A., BERRY, L. L. A conceptual model of service quality and its implications for future research. Journal of Marketing, v. 49, n. 4, p. 41-50, 1985.

SERVQUAL: a multiple-item scale for measuring consumer perceptions of service quality. Journal of Retailing, v. 64 , n. 1, p. 12-39, 1988.

Alternatives scales for measuring service quality: a comparative assessment based on psychometric and diagnostic criteria. Journal of Retailing, v. 70, n. 3, p. 201-230, 1994.

POFFO, G. D.; MARINHO, S. V. Qualidade na percepção discente do curso de Administração. Revista Gestão Universitária na América Latina - GUAL, Florianópolis, v. 6, n. 2, p. 210-230, abr. 2013.

RAZAVI, S. M.; SAFARI, H.; SHAFIE, H.; KHORAM, K. Relationships among Service Quality, Customer Satisfaction and Customer Perceived Value: Evidence from Iran's Software Industry. Journal of Management and Strategy, v. 3, n. 3, p. 28, 2012.

SOUZA, A. S.; SILVA, C. P.; RODRIGUES, M. S. Avaliação da Qualidade dos Serviços: Uma Análise dos Dados e a Metodologia Adotada. Revista de Ciências da Administração, v. 6, n.12, jul./dez. 2004.

TEAS, R. K. Expectations, performance evaluation and consumer's perceptions of quality. Journal of Marketing, v. 57, n. 4, p. 18-34, 1993.

TEIXEIRA, E. As três metodologias: acadêmica, da ciência e da pesquisa. 2. ed. Petrópolis, RJ: Vozes, 2006. 
THIRY-CHERQUES, H. R. Saturação em pesquisa qualitativa: estimativa empírica de dimensionamento. PMKT Revista Brasileira de Pesquisas de Marketing Opinião e Mídia, n. 3, set. 2009.

WALTER, S. A.; TONTINI, G.; DOMINGUES, M. J. C. S. Identificando oportunidades de melhoria em um curso superior através da análise da satisfação dos alunos. In: ENCONTRO DA ASSOCIAÇÃO NACIONAL DE PÓS-GRADUAÇÃO E PESQUISA EM ADMINISTRAÇÃO, 29., 2005, Brasília. Anais... Brasília: ANPAD, 2005.

ZEITHAML, V. A.; BITNER, M. J. Marketing de Serviços: a empresa com foco no cliente. 2. ed. Porto Alegre: Bookman, 2003.

ZEITHAML, V. A.; BITNER, M. J.; GREMLER, D. D. Marketing de serviços: a empresa com foco no cliente. 5. ed. Porto Alegre: Bookman, 2011. 